\title{
Potential use of microbial thermo-bioplastic polyhydroxyalkanoate as promising tissue engineering biomaterial in biomedicine
}

\begin{abstract}
Biologically-synthesized plastic, polyhydroxyalkanoates (PHAa), have been attracting interest in biomedecine due to its similar physical properties to synthetic plastics. Due to its biocompatibility and biodegradability, poly(3-hydroxybutyrates) (PHBs) and related copolymers, mostly poly(3-hydroxybutyrate-co-3-hydroxyvalerates) (PHBVs) has been widely evaluated as carriers for drug delivery or scaffolds in a wide variety of tissue engineering applications. Screening and selection of novel suitable (extremophilic) bacterial strains, low-cost renewable carbon sources, efficient fermentation technologies of natural and recombinant microorganisms and PHA recovery processes are very interesting aspects that should be taken into consideration for the commercialization of microbial PHAs with industrial potential. This review aims to illustrate the start-up of PHA research in biomedicine by providing a summary of their unique physiochemical and mechanical properties for use as biomedical materials for bone, cartilage, cardiovascular, nerve conduit, skin and esophagus tissue engineering.
\end{abstract}

Keywords: bioplastics, PHA-producing bacteria, extremophiles, tissue engineering, biocompatible, biomedicine
Volume 4 Issue 2 - 2018

\author{
Mohamed Neifar, Fatma Naili, Habib \\ Chouchane, Ameur Cherif \\ LR Biotechnology and Bio-Geo Resources Valorization, \\ University of Manouba, Tunisia
}

Correspondence: Ameur Cherif, LR Biotechnology and Bio-Geo Resources Valorization (LR I IES3 I), Higher Institute for Biotechnology, University of Manouba Biotechpole of Sidi Thabet, 2020, Sidi Thabet, Ariana, Tunisia, Tel/Fax 70527882 , Email cherif.ameur@gmail.com

Received: July 27, 2017| Published: March 15, 2018

\section{Introduction}

The potential of bio based plastics for replacement of petrochemical plastics is $90 \%$, corresponding to 240 million tons per year. ${ }^{1}$ Bio-based materials such as polynucleotides, polyamides, polysaccharides, polyoxoesters, polythioesters, polyanhydrides, polyisoprenoids and polyphenols are potential candidates for substitution of synthetic plastics. ${ }^{2}$ Polyhydroxyalkanoates (PHAs), belonging the group of polyesters, have been received a great deal of attention because they possess biodegradable thermoplastic properties. ${ }^{3}$

PHAs are synthesized by microorganisms under unbalanced growth conditions. They act as ideal storage compounds due to its insolubility inside cytoplasm, which exert negligible increase in osmotic pressure. ${ }^{4}$ PHA producing microbes as storage biomaterials are able to survive during starvation period compared to those non PHA-producing microbes as these energy-reserve biomaterials slow down the cell autolysis and subsequently its mortality. ${ }^{5}$ Among the more than 300 PHA-producer strains, only a limited number of microorganisms have been employed for the biosynthesis and commercialization of PHAs including Alcaligenes latus, Cupriavidus necator, Pseudomonas oleovorans and Bacillus megaterium, which are able to grow on different low cost carbon sources including plant oils or wastes to produce PHA. ${ }^{6}$ Some bacteria have been described as producer of PHA as much as $90 \%(\mathrm{w} / \mathrm{w})$ of dry cells during depletion of essential nutrients such as nitrogen, phosphorus or magnesium. ${ }^{7}$ A vast number of PHAs from extremophiles were reported over the last two decades (Table 1). For examples, the highly halotolerant bacterium Halomonas boliviensis LC1 could grow and produce $56 \%$ CDM of scl-PHA P3HB from starch hydrolysate under saline conditions $(0.77 \mathrm{M} \mathrm{NaCl})$ while the thermophilic bacterium Thermus thermophilus HB8 synthesized up to $35.6 \%$ CDM of scl-mcl-PHA copolymer from whey at a high cultivation temperature of $70^{\circ} \mathrm{C}{ }^{8,9}$

Table I Some extremophilic PHA-producing microbial strains

\begin{tabular}{|c|c|c|c|c|c|}
\hline Microorganisms & Sample nature & Extremophily & $\begin{array}{l}\text { Carbon } \\
\text { source }\end{array}$ & $\begin{array}{l}\text { Monomere/polymere } \\
\text { PHA / PHA nature }\end{array}$ & Ref. \\
\hline $\begin{array}{l}\text { Halogeometricum } \\
\text { borinquense (TN9) }\end{array}$ & $\begin{array}{l}\text { brine and sediment samples of } \\
\text { solar salterns of India }\end{array}$ & $20 \% \mathrm{NaCl}$ & Glucose & P3HB (thermostable) & {$[10]$} \\
\hline $\begin{array}{l}\text { Halogeometricum } \\
\text { borinquense (E3) }\end{array}$ & Tuzkoy Salt Mine (TK) & $25 \% \mathrm{NaCl}$ & $\begin{array}{l}\text { Corn } \\
\text { starch }\end{array}$ & $\mathrm{P}(\mathrm{HB}-\mathrm{co}-\mathrm{HV})$ & {$[\mathrm{II}]$} \\
\hline Halomonas boliviensis & $\begin{array}{l}\text { Skin of the red sea squirt } \\
\text { Halocynthia papillosa }\end{array}$ & $\begin{array}{l}\text { I2\% Nacl pH 8.0- } \\
10.0\end{array}$ & $\begin{array}{l}\text { Starch } \\
\text { hydrolysate }\end{array}$ & $\begin{array}{l}\text { P3HB } \\
\text { scl-PHA (thermostable) }\end{array}$ & $\begin{array}{l}{[12]} \\
{[13]}\end{array}$ \\
\hline Thermus Thermophilus & 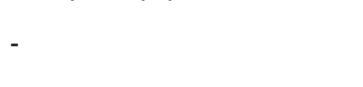 & $\begin{array}{l}65^{\circ} \mathrm{C} \\
\mathrm{pH} 8.0\end{array}$ & $\begin{array}{l}\text { sodium } \\
\text { gluconate }\end{array}$ & $\begin{array}{l}\text { scl-mcl- PHA } \\
\text { (thermostable) }\end{array}$ & $\begin{array}{l}{[14]} \\
{[15]}\end{array}$ \\
\hline Thermus thermophilus HB8 & & $60-75^{\circ} \mathrm{C}$ & & P3HB (thermostable) & [16] \\
\hline Pseudomonas sp. SG4502 & - & $55^{\circ} \mathrm{C}$ & Glucose & $\begin{array}{l}\text { P3HB } \\
\text { (thermostable polymer) }\end{array}$ & [17] \\
\hline
\end{tabular}


Table continued....

\begin{tabular}{|c|c|c|c|c|c|}
\hline Microorganisms & Sample nature & Extremophily & $\begin{array}{l}\text { Carbon } \\
\text { source }\end{array}$ & $\begin{array}{l}\text { Monomere/polymere } \\
\text { PHA / PHA nature }\end{array}$ & Ref. \\
\hline Pseudomonas oleovorans & - & - & fatty acid & mcl-PHA & [18] \\
\hline Bacillus cereus PW3A & polluted water sample & - & Glucose & $\begin{array}{l}\text { P3HB (thermal and } \\
\text { mechanical properties) }\end{array}$ & [19] \\
\hline Bacillus Megaterium & Yufutsu gas field & $40^{\circ} \mathrm{C}$ & Glucose & $3 \mathrm{HB}, 3 \mathrm{HV}, 3 \mathrm{HHx}$ & [20] \\
\hline $\begin{array}{l}\text { Cupriavidus necator } \mathrm{HI} 6 \\
\text { (thermophile) }\end{array}$ & Hot spring in Southern Taiwan & $50^{\circ} \mathrm{C}$ & Glucose & Thermostable PHB & {$[21]$} \\
\hline
\end{tabular}

The manipulation of natural and recombinant microbial producers of PHA to achieve high PHA production has been the subject of many studies. ${ }^{4,7}$ E. coli has been the selected host for genetic techniques devised to introduce the PHA biosynthetic genes, improve their expression, provide suitable quality and concentration of substrates to the PHA synthase, as well as to modify the host strains to improve their performance in the bioreactor. ${ }^{22}$ Nowadays, microbial PHAs continue to attract increasing industrial interest as renewable, biodegradable, biocompatible, and extremely versatile thermoplastics. ${ }^{23}$ Microbial PHAs are the only waterproof thermoplastic materials available that are fully biodegraded in aerobic and anaerobic environments. There are according to their monomer composition: short-chain length (SCL) PHAs and medium-chain length (MCL) PHAs. SCLPHAs are polymers of 3-hydroxyacid monomers with a chain length of 3 to 5 carbon atoms, such as poly(3-hydroxybutyrate) (PHB, the most common PHA); whereas MCL-PHAs contain 3-hydroxyacid monomers with carbon atoms between 6 to 16 . All of them are optically active compounds. ${ }^{24}$ Around 200 different monomer constituents were found in the polymers. ${ }^{25}$ This versatility is due in particular to the wide substrates of the PHA-synthesizing enzymes, and gives PHAs an extended spectrum of associated properties which is a clear advantage compared to other bioplastics. PHAs are biocompatible and for this reason they have also attracted attention as raw material to be used in medical devices. ${ }^{26}$ PHA has been generally manufactured for polymer films, non-woven materials, and pharmaceutical products used in transplantology, surgery, and in tissue engineering. ${ }^{27}$ Although PHAs have the potential to be used as tissue engineering biomaterials, only a few of them have been produced industrially. ${ }^{28,29}$ Nowadays PHAs types such as PHB, PHBV, and PHBHHx are used as substitutes for cardiovascular tissue, heart valve tissue, nerve conduit tissue, skin tissue, subcutaneous tissue, esophagus tissue, cartilage tissue, and bone tissue (Figure 1).
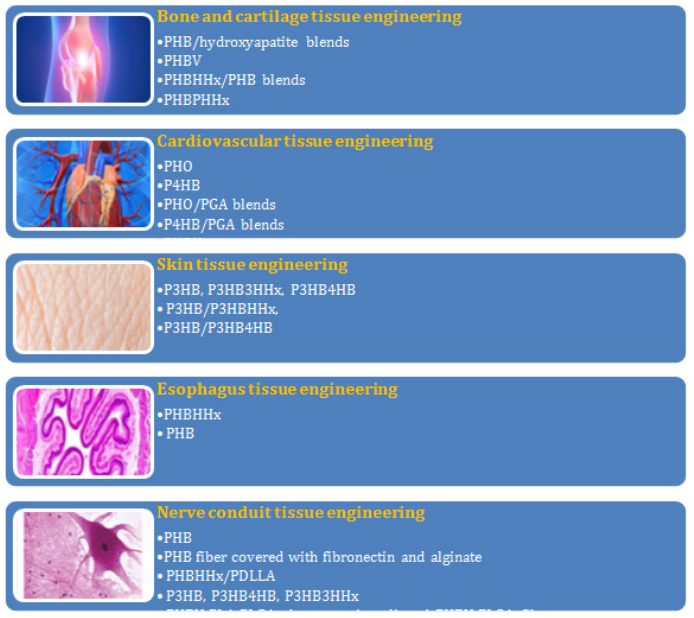

Figure I Tissue engineering applications of PHAs. ${ }^{22}$
In tissue engineering, the cells are grown in vitro on biopolymers to construct tissue for implantation purposes. ${ }^{30} \mathrm{~A}$ high level of biocompatibility is usually needed before foreign biomaterials can be incorporated into human body. Shape, surface porosity, chemistry of the biomaterials and the environment of the tissue play important roles in biocompatibility. ${ }^{31-33}$ PHAs have shown good potential as medical implant biomaterials. For examples, Neural stem cells (NSCs) grown on/in PHA scaffolds may be useful for repairing central nervous system (CNS) injury. ${ }^{34}$ Among the PHA family members, PHBHHx appears to have the strongest potential to promote NSC differentiation into neurons. It has been suggested that PHBHHx nanofiber scaffolds that promote NSC growth and differentiation could be developed for treating CNS defects.

Cells for bone and cartilage regeneration have been also evaluated for their proliferative and differentiative responses when inoculated into PHBHHx-based scaffolds. ${ }^{35,36}$ It has been reported that PHBHHx scaffolds increase both chondrocyte proliferation and protein secretion in rabbit articular cartilage cells seeded onto them. ${ }^{37,38}$

Considering that its strength and elastic properties can be adjusted by changing its monomer contents, PHBHHx could be tailored to meet the requirements for regenerating both bone and soft tissues. PHBHHx, with its excellent mechanical and thermal properties, has been used as a scaffold for tissue-engineered cardiovascular products. ${ }^{39,40}$

\section{Conclusion}

In conclusion, microbial PHAs offer great practical potential as tissue engineering biomaterials. New targets and strategies for the improvement of PHA production will certainly be developed in the next future, including screening and selection of novel extrophilic PHA producers and tailor-made PHAs with desired monomer compositions. In order to design a completely sustainable PHA production process, strains should be further metabolically engineered to produce PHAs up to sufficiently high polymer content with high productivity from the most inexpensive carbon source through finecontrolled fermentation schemes. With novel composite material generation coupled with technical innovations, microbial PHAs may be of clinical benefit in regenerating a variety of tissues.

\section{Acknowledgements}

None.

\section{Conflict of interest}

The authors declare no conflict of interest.

\section{References}

1. Akaraonye E, Moreno C, Knowles JC, et al. Poly(3-hydroxybutyrate) 
production by Bacillus cereus SPV using sugarcane molasses as the main carbon source. Biotechnol J. 2012;7(2):293-303.

2. Steinbüchel A. Perspectives for biotechnological production and utilization of biopolymers: metabolic engineering of polyhydroxyalkanoate biosynthesis pathways as a successful example. Macromolecular bioscience. 2001;1(1):1-24.

3. Albuquerque MGE, Eiroa M, Torres C, et al. Strategies for the developmen of a side stream process for polyhydroxyalkanoate (PHA) production from sugar cane molasses. J Biotechnol. 2007;130(4):411-421.

4. Keshavarz T, Roy I. Polyhydroxyalkanoates: bioplastics with a green agenda. Curr Opin Microbiol. 2010;13(3):321-326.

5. Macrae RM, Wilkinson JF. Poly-beta-hyroxybutyrate metabolism in washed suspensions of Bacillus cereus and Bacillus megaterium. J Gen Microbiol. 1958;19:210-222.

6. Tan KL, Vlisidou I, Wood W. Ecdysone mediates the development of immunity in the Drosophila embryo. Curr Biol. 2014;24(10):1145-1152.

7. Madison LL, Huisman GW. Metabolic engineering of poly (3-hydroxyalkanoates): From DNA to plastic. Microbiol Mol Biol Rev. 1999;63(1):21-53.

8. Pantazaki AA, Papaneophytou CP, Pritsa AG, et al. Production of polyhydroxyalkanoates from whey by Thermus thermophilus HB8. Process Biochem. 2009;44(8):847-853

9. Quillaguamán J, Hashim S, Bento $\mathrm{F}$, et al. Poly ( $\beta$-hydroxybutyrate) production by a moderate halophile, Halomonas boliviensis LC1 using starch hydrolysate as substrate. J Appl Microbiol. 2005;99(1):151-157.

10. Salgaonkar BB, Mani K, Braganc JM. Accumulation of polyhydroxyalkanoates by halophilic archaea isolated from traditional solar salterns of India. Extremophiles. 2013;17(5):787-795.

11. Salgaonkar BB, Bragança JM. Biosynthesis of poly (3-hydroxybutyrateco-3-hydroxyvalerate) by Halogeometricum borinquense strain E3. Int J Biol Macromol. 2015;78:339-346.

12. Williamson A, De Santi C, Altermark B, et al. Complete genome sequence of Halomonas sp. R5-57. Stand Genomic Sci. 2016;11(1):62.

13. Rivera-Terceros P, Tito-Claros E, Torrico S, et al. Production of poly(3hydroxybutyrate) by Halomonas boliviensis in an air-lift reactor. $J$ Biol Res (Thessalon). 2015;22(1):8.

14. Pantazaki AA, Ioannou AK, Kyriakidis DA. A thermostable $\beta$-ketothiolase of polyhydroxyalkanoates (PHAs) in Thermus thermophilus: Purification and biochemical properties. Mol Cell Biochem. 2005;269(1-2):27-36.

15. Satoh $\mathrm{Y}$, Tajima $\mathrm{K}$, Nakamoto $\mathrm{S}$, et al. Isolation of a thermotoleran bacterium producing medium-chain-length polyhydroxyalkanoate. $J \mathrm{Appl}$ Microbiol. 2011;111(4):811-817.

16. Tajima $\mathrm{K}$, Han $\mathrm{X}$, Hashimoto $\mathrm{Y}$, et al. In vitro synthesis of polyhydroxyalkanoates using thermostable acetyl-CoA synthetase, CoA transferase, and PHA synthase from thermotorelant bacteria. $J$ Biosci Bioeng. 2016;122(6):660-665.

17. Tajima K, Han X, Satoh Y, et al. In vitro synthesis of polyhydroxyalkanoate (PHA) incorporating lactate (LA) with a block sequence by using a newly engineered thermostable PHA synthase from Pseudomonas sp. SG4502 with acquired LA-polymerizing activity. Appl Microbiol Biotechnol. 2011;94(2):365-376

18. Huisman GW, Wonink E, Meima R, et al. Metabolism of poly(3- hydroxyalkanoates) (PHAs) by Pseudomonas oleovorans. Identification and sequences of genes and function of the encoded proteins in the synthesis and degradation of PHA. J Biol Chem. 1991;266(4):2191-2198.

19. Babruwad PR, Prabhu SU, Upadhyaya KP, et al. Production and characterization of thermostable polyhydroxybutyrate from Bacillus cereus PW3A. J Biochem Tech. 2015;6(3):990-995.

20. Tajima K, Igari T, Nishimura D, et al. Isolation and characterization of Bacillus sp. INT005 accumulating polyhydroxyalkanoate (PHA) from gas field soil. J Biosci Bioeng. 2003;95(1):77-81.

21. Shafie NA, Lau NS, Ramachandran H, et al. Complete genome sequences of three cupriavidus strains isolated from various Malaysian environments. Genome Announc. 2017;5(3):e01498-16.

22. Ke Y, Zhang XY, Ramakrishna S, et al. Reactive blends based on polyhydroxyalkanoates: preparation and biomedical application. Mater Sci Eng C Mater Biol Appl. 2017;70(Pt 2):1107-1119.

23. Suriyamongkol P, Weselake R, Narine S, et al. Biotechnological approaches for the production of polyhydroxyalkanoates in microorganisms and plants. A review. Biotechnol Adv. 2007;25(2):148-175.

24. David J Anderson, Annathurai Gnanasambandam, Edwina Mills, et al. Synthesis of short-chain-length/medium-chain length polyhydroxyalkanoate (PHA) copolymers in peroxisomes of transgenic sugarcane plants. Tropical Plant Biology. 2011;4(3-4):170-184.

25. Steinbüchel A, Lütke-Eversloh T. Metabolic engineering and pathway construction for biotechnological production of relevant polyhydroxyalkanoates in microorganisms. Biochemical Engineering Journal. 2003;16(2):81-96.

26. Wu Q, Wang Y, Chen GQ. Medical application of microbial biopolyesters polyhydroxyalkanoates. Artif Cells Blood Substit Immobil Biotechnol. 2009;37(1):1-12.

27. Shrivastav A, Kim HY, Kim YR. Advances in the applications of polyhydroxyalkanoate nanoparticles for novel drug delivery system. Biomed Res Int. 2013:581684.

28. Chen C, Yu PHF, Cheung MK. Hydrogen bonding, miscibility, crystallization, and thermal stability in blends of biodegradable polyhydroxyalkanoates and polar small molecules of 4-tert-Butylphenol. J Appl Polym Sci. 2005(98):736-745.

29. Yuan Gao, Lijun Kong, Ling Zhang, et al. Improvement of mechanical properties of poly(dl-lactide) films by blending of poly(3-hydroxybutyrateco-3-hydroxyhexanoate). Eur Polym J. 2006;42(4):764-775.

30. Mack HB, Mai R, Lauer G, et al. Adaptation of myosin heavy chain mRNA expression after implantation of poly (3) hydroxybutyrate scaffolds in rat m. latissimus dorsi. J Physiol Pharmacol. 2008(59):95-103.

31. Chen GQ, Wu Q. The application of polyhydroxyalkanoates as tissue engineering materials. Biomaterials. 2005;26(33):6565-6578.

32. Köse GT, Korkusuz F, Ozkul A, et al. Tissue engineered cartilage on collagen and PHBV matrices. Biomaterials. 2005;26(25):5187-5197.

33. Sun JY, Jun Wu, Haiyan Li, et al. Macroporous poly (3-hydroxybutyrateco-3-hydroxyvalerate) matrices for cartilage tissue engineering. Eur Polym J. 2005;41(10):2443-2449.

34. Wang F, Lee SY. Poly(3-hydroxybutyrate) production with high productivity and high polymer content by a fed-batch culture of Alcaligenes latus under nitrogen limitation. Appl Environ Microbiol. 1997;63(9):3703-3706 
35. You ML, Peng G, Li J, et al. Chondrogenic differentiation of human bone marrow mesenchymal stem cells on polyhydroxyalkanoate (PHA) scaffolds coated with PHA granule binding protein PhaP fused with RGD peptide. Biomaterials. 2011;32(9):2305-2313.

36. Luklinska ZB, Bonfield W. Morphology and ultrastructure of the interface between hydroxyapatite-polyhydroxybutyrate composite implant and bone. Sci Mater Med. 1997;8(6):379-383.

37. Zheng Z, Bei FF, Tian HL, et al. Effects of crystallization of polyhydroxyalkanoate blend on surface physicochemical properties and interactions with rabbit articular cartilage chondrocytes. Biomaterials. $2005 ; 26(17): 3537-3548$
38. Chun YS, Kim WN, Thermal properties of blends of poly(hydroxybutyrateco-hydroxyvalerate) and poly(styrene-co-acrylonitrile). Appl Polym Sci. 2000;77(3):673-679.

39. Zhang L, Zhenhuan Zheng, Jing Xi, et al. Improved mechanical property and biocompatibility of poly (3-hydroxybutyrate-co-3-hydroxyhexanoate) for blood vessel tissue engineering by blending with poly (propylene carbonate). Eur Polym J. 2007;43(7):2975-2986.

40. Hoerstrup SP, Sodian R, Daebritz S, et al. Functional living trileaflet heart valves grown in vitro. Circulation. 2000;102(19 Suppl 3):44-49. 